\title{
Melting and Transformation Behavior of $\gamma$ Form Nylon 6 under High Pressure
}

\author{
Nobuyasu HiRAmatsu and Susumu HiraKawa \\ Department of Applied Physics, Faculty of Science, Fukuoka University, \\ 11 Nanakuma, Nishi-ku, Fukuoka 814-01, Japan.
}

(Received March 7, 1981)

\begin{abstract}
Thermal behavior under high pressure of the $\gamma$ form nylon 6 obtained by iodine treatment was investigated by means of a high pressure differential thermal analysis. The crystalline structures which resulted in the endo- and exo-thermic peaks in the thermogram were examined with the wide angle $\mathrm{X}$-ray diffraction measurement. Under relatively low pressure $(170-2000$ $\mathrm{kg} \mathrm{cm}^{-2}$ ), two endothermic peaks were found. With increasing pressure, the lower temperature side endotherm due to the melting of the $\gamma$ form crystal became small, while the higher one due to the melting of the converted $\alpha$ form crystal became large. Under high pressure (above $2000 \mathrm{~kg} \mathrm{~cm}^{-2}$ ) an endotherm due to the melting of the converted $\alpha$ form crystal and an exotherm were observed. This exotherm is attributed to the $\gamma$ to $\alpha$ form transformation. In this case, the transformation occurred without melting the $\gamma$ form crystal, in contrast to the situation at atmospheric pressure. The pressure dependences of the melting peak temperatures of the $\alpha$ form and the $\gamma$ form were almost the same and equal to $18^{\circ} \mathrm{C}$ per $1000 \mathrm{~kg} \mathrm{~cm}^{-2}$.

KEY WORDS Nylon $6 / \gamma$ Form / High Pressure / Melting Behavior $/ \gamma-\alpha$

Transformation / Iodine Treatment / Pressure Dependence /
\end{abstract}

It is well known that nylon 6 has two kinds of crystal forms. $^{1,2}$ One is called the $\alpha$ form and consists of fully extended planar zigzag chains, in which adjacent antiparallel chains are joined to each other by the $\mathrm{N}-\mathrm{H} \cdots$ O hydrogen bonds. This form can be obtained by crystallization from the melt by slow cooling. The other is called $\gamma$ form. This crystal is composed of pleated sheets of parallel chains joined by hydrogen bonds. This form appears on quenching from the melt ${ }^{3}$ or treatment of the $\alpha$ form with an iodine potassium-iodine aqueous solution..$^{4-11}$ The crystals of both forms are monoclinic. $^{1,2}$ The structure of the $\gamma$ form can be also regarded as a pseudohexagonal structure.

The condition for the $\gamma$ to $\alpha$ form transformation has been studied by several authors. ${ }^{10-13} \mathrm{Abu}$-isa ${ }^{11}$ has reported that the $\gamma$ form nylon 6 obtained by iodine treatment is not transformed into the $\alpha$ form till the temperature reaches its melting point. On the other hand, Miyasaka and Ishikawa ${ }^{10}$ have reported that the transformation occurs at a temperature lower than the melting point when a fiber type sample undergoes stress along its fiber axis.
However, the authors ${ }^{10,11}$ above have considered the mechanism for the transformation on the basis of the results obtained at atmospheric pressure. It may be expected that examination at various pressures would provide a more accurate understanding of this transformation behavior.

The melting behavior of the $\alpha$ form nylon 6 under elevated pressure was examined by Gogolewski and Pennings ${ }^{14,15}$ by the dilatometric method.

In the present investigation, to clarify the melting and transformation behavior under high pressure of the $\gamma$ form of nylon 6 obtained by the iodinetreatment, high pressure differential thermal analysis (DTA) and wide angle X-ray diffraction (WAXD) measurements were carried out. From these results, the effect of pressure on the melting and transformation behavior is discussed.

\section{EXPERIMENTAL}

\section{(1) Sample Preparation}

Amilan (Toray) was used as the original sample of nylon 6 . The relative viscosity of this sample was 
found to be 2.86 when measured at $25^{\circ} \mathrm{C}$ in a 10 $\mathrm{g} \mathrm{dm}^{-3}$ solution in $98 \% \mathrm{H}_{2} \mathrm{SO}_{4}$. This original sample had the $\alpha$ form crystal structure, as confirmed by the WAXD measurement. The $\gamma$ form nylon 6 was prepared as follows. After the films were made by melting the original sample, they were stretched to about twice their original length with a roller at room temperature. These films (about $80 \mu \mathrm{m}$ in thickness) were left immersed in a potassium iodide-iodine aqueous solution (KI, $0.46 \mathrm{~mol} \mathrm{dm}^{-3}$; $\mathrm{I}_{2}, 0.21 \mathrm{~mol} \mathrm{dm}^{-3}$ ) for two days or more, causing them to take on the $\gamma$ form. After that, the films were sufficiently washed with acetone to remove the iodine and were dried and stored in vacuum to avoid any effects of moisture. The structure of these samples was confirmed to be the $\gamma$ form by the WAXD measurement.

\section{(2) Experimental Apparatus and Procedure}

The design of the high pressure DTA cell and the schematic diagram of the measuring system were reported in a previous paper. ${ }^{16}$ Since this apparatus had a heater set inside the high pressure vessel, the sample could be heated up to $400^{\circ} \mathrm{C}$ and rapidly cooled (about $100^{\circ} \mathrm{C} \mathrm{min}^{-1}$ ). The temperature was precisely controlled within $\pm 0.5^{\circ} \mathrm{C}$. Pressure measurements were directly performed using a Bourdon gauge (Heise) with an accuracy of \pm 20 $\mathrm{kg} \mathrm{cm}^{-2}$. Low viscosity silicone oil (Shin-Etsu Chemical KF 96, 10 cs) was used as the pressure transmitting fluid.

The heating rate in the DTA measurement was about $10^{\circ} \mathrm{C} \mathrm{min}^{-1}$. The weight of the film-shaped sample used in this measurement was about $10 \mathrm{mg}$. The sample was loosely wound round the thermocouple in order to avoid the effect of strain on the transformation behavior.

It was difficult to obtain a thermogram at atmospheric pressure using the high pressure DTA apparatus because of the convection of the transmitting fluid, and so melting behavior at atmospheric pressure was measured with a differential scanning calorimetry (DSC) apparatus (Rigaku Denki) at a heating rate of $10^{\circ} \mathrm{C} \mathrm{min}^{-1}$. The sample weight used was about $10 \mathrm{mg}$.

The procedure for preparing the sample for the WAXD measurement was as follows. The sample was heated up to a desired temperature at a heating rate of $10^{\circ} \mathrm{C} \mathrm{min}^{-1}$ in the DTA cell.

The desired temperature was maintained for a given period of time, when necessary. The sample was then rapidly cooled (about $100^{\circ} \mathrm{C} \mathrm{min}^{-1}$ ) to room temperature.

The WAXD pattern was obtained at atmospheric pressure and room temperature with nickel filtered $\mathrm{Cu} K_{\alpha}$ radiation using a scintillation counter system (Japan Electric Optics Laboratory). To verify the transformation under high pressure, a direct measurement of the WAXD was carried out under high pressure using a high pressure and high temperature X-ray diffraction measuring system equipped with a position sensitive proportional counter (PSPC). The details of the system are reported in ref. 17. Patterns of the WAXD were observed at $2500 \mathrm{~kg} \mathrm{~cm}^{-2}$ with increasing temperature at a heating rate of about $0.3^{\circ} \mathrm{C} \min ^{-1}$.

\section{RESULTS AND DISCUSSION}

Figure 1 shows the melting processes of the $\gamma$ form of nylon 6 at atmospheric pressure and at the various pressures indicated in the figure. It was noticed that at atmospheric pressure, only one endotherm appeared in the thermogram, and that with increasing pressure, a new endothermic peak appeared and grew at a higher temperature position. The lower temperature side endotherm became small. An exothermic peak was apparent above about $2000 \mathrm{~kg} \mathrm{~cm}^{-2}$. The pressure dependences of the peak temperatures for the two endotherms and one exotherm are shown in Figure 2. The two endothermic peaks showed nearly the same pressure dependence; about $18^{\circ} \mathrm{C}$ per $1000 \mathrm{~kg} \mathrm{~cm}^{-2}$. This value agrees approximately with that of the melting point of the $\alpha$ form reported by Gogolewski and Pennings. ${ }^{14}$ The pressure dependence of the exothermic peak temperature, which was about $8.5^{\circ} \mathrm{C}$ per $1000 \mathrm{~kg} \mathrm{~cm}^{-2}$, was smaller than that of the endotherms.

The DTA thermograms indicate a complex melting process. However, this result has not been reported yet. In order to examine the origin of these peaks in the thermograms, the structure change in the sample treated under high pressure was examined by the WAXD measurement.

First, in order to examine the origin of the endotherm and exotherm observed above about $2000 \mathrm{~kg} \mathrm{~cm}^{-2}$, the DTA thermogram of the $\alpha$ form was compared with that of the $\gamma$ form. The DTA thermograms of the melting (1st run)- 


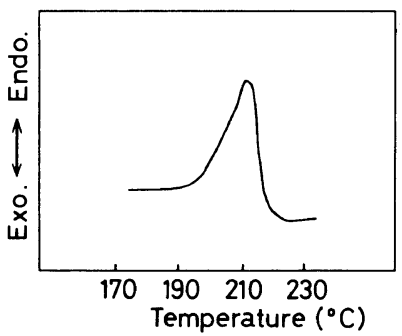

(a)

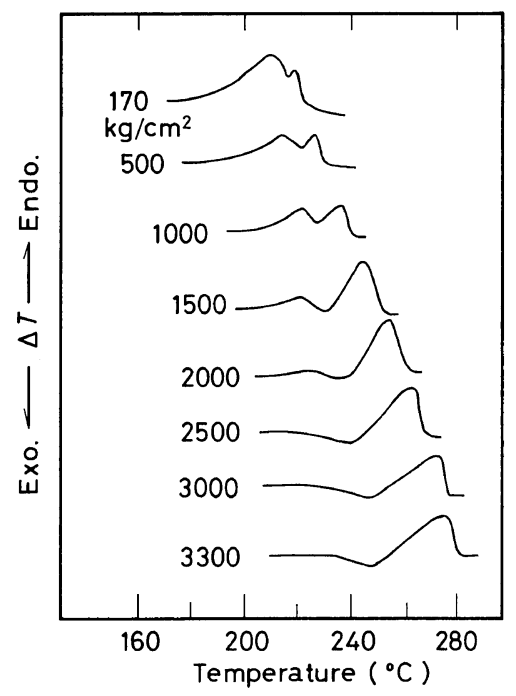

(b)

Figure 1. (a) DSC thermogram of the $\gamma$ form sample observed at atmospheric pressure. (b) DTA thermograms under various pressures on heating of the $\gamma$ form of nylon 6 .

crystallization-remelting ( 2 nd run) process at 3300 $\mathrm{kg} \mathrm{cm}^{-2}$ are shown in Figure 3. The second run corresponds to the melting of the $\alpha$ form, since it was confirmed by WAXD measurement that all the samples crystallized from the melt at various pressures had the $\alpha$ form structure. The WAXD pattern of the sample crystallized from the melt at 3300 $\mathrm{kg} \mathrm{cm}{ }^{-2}$ and at a cooling rate of $10^{\circ} \mathrm{C} \mathrm{min}^{-1}$ is also shown in Figure 3. The WAXD pattern indicates the typical $\alpha$ form structure. The exothermic peak, appearing in the first run, disappears in the second run. The temperature and shape of the endothermic peak in the first run are almost the same as those in the second run. Therefore, it is assumed that the endotherm observed at $3300 \mathrm{~kg} \mathrm{~cm}^{-2}$ is due to the

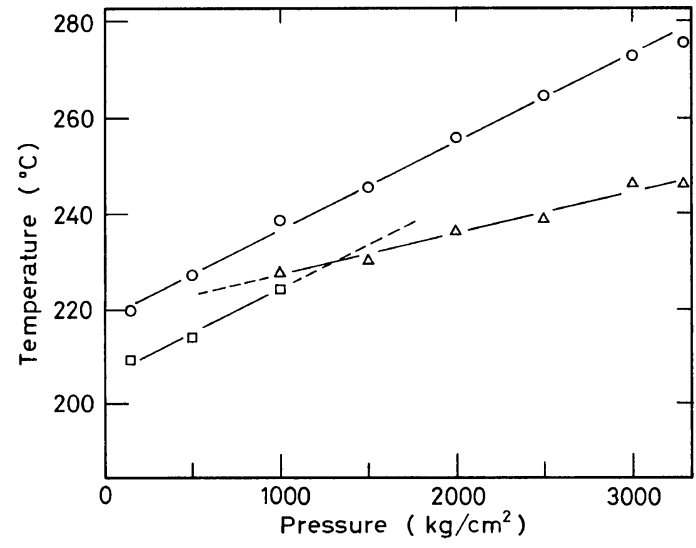

Figure 2. Pressure dependence of peak temperatures in the thermograms shown in Figure 1: $\bigcirc$, higher temperature side endothermic peak; $\square$, lower temperature side endothermic peak; $\triangle$, exothermic peak.

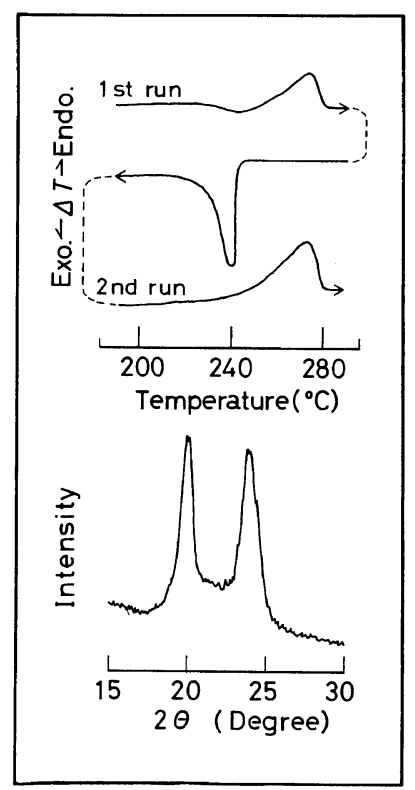

Figure 3. DTA thermogram of melting, crystallization, and remelting process at $3300 \mathrm{~kg} \mathrm{~cm}^{-2}$ and WAXD pattern of the sample crystallized from the melt at $3300 \mathrm{~kg} \mathrm{~cm}^{-2}$. First and second runs correspond to the melting processes of the $\gamma$ and $\alpha$ form crystals, respectively.

melting of the $\alpha$ form, and that the transformation occurs at a temperature lower than that of the endotherm when the temperature increases grad- 


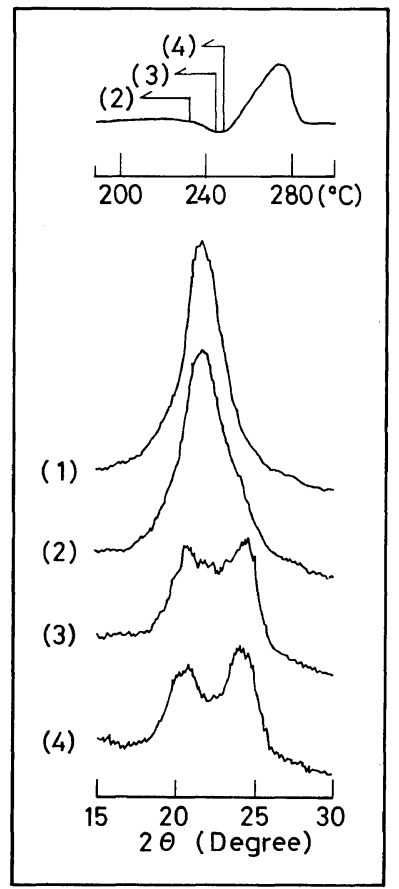

Figure 4. DTA thermogram on heating of the $\gamma$ form crystal at $3300 \mathrm{~kg} \mathrm{~cm}^{-2}$ and WAXD patterns of the samples heated up to various temperatures, (2) $233^{\circ} \mathrm{C}$, (3) $245^{\circ} \mathrm{C}$, and (4) $248^{\circ} \mathrm{C}$ at $3300 \mathrm{~kg} \mathrm{~cm}^{-2}$ followed by rapid cooling. Pattern (1) is that of the starting sample of the $\gamma$ form.

ually at $3300 \mathrm{~kg} \mathrm{~cm}^{-2}$.

These assumptions were checked out by WAXD measurement of the sample heated up to each given temperature under various pressures. The result obtained at $3300 \mathrm{~kg} \mathrm{~cm}^{-2}$ is shown in Figure 4. In this figure, the WAXD pattern of the starting sample of the $\gamma$ form is also shown for comparison. It should be noted that the transformation does not occur in the sample heated up to $233^{\circ} \mathrm{C}$ which corresponds to the beginning temperature of the exothermic peak at a heating rate of $10^{\circ} \mathrm{C} \mathrm{min}^{-1}$. When the sample is heated up to the peak temperature of the exothermic peak $\left(245-248^{\circ} \mathrm{C}\right)$, the $\gamma$ form is completely transformed into the $\alpha$ form. From this fact, it can be concluded that the endothermic peak located at a temperature higher than that of the exothermic peak, is due to the melting of the $\alpha$ form, and that the transformation occurs in the temperature region of the exotherm. $215^{\circ} \mathrm{C}$

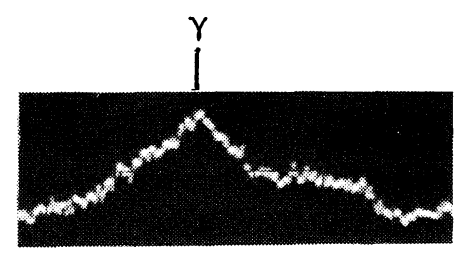

$218^{\circ} \mathrm{C}$

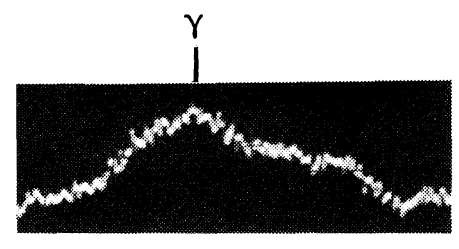

$220^{\circ} \mathrm{C}$

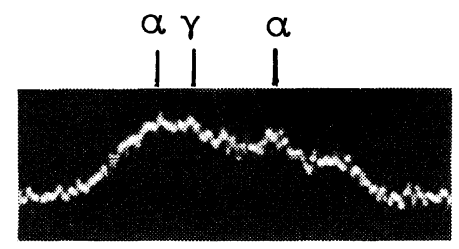

$222^{\circ} \mathrm{C}$

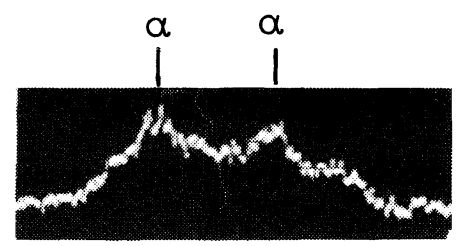

$2 \theta$

Figure 5. WAXD patterns measured with PSPC for the $\gamma$ form sample observed at $2500 \mathrm{~kg} \mathrm{~cm}^{-2}$ and various temperatures indicated in the figure with increasing temperature at a heating rate of about $0.3^{\circ} \mathrm{C} \mathrm{min}^{-1}$.

To verify the transformation under high pressure, a direct observation of the transformation behavior was carried out by the PSPC system. The WAXD patterns of the sample at $2500 \mathrm{~kg} \mathrm{~cm}^{-2}$ were recorded as the temperature increased. The transformation behavior at $2500 \mathrm{~kg} \mathrm{~cm}^{-2}$ is expected to be similar to that at $3300 \mathrm{~kg} \mathrm{~cm}^{-2}$, since the melting thermogram of the $\gamma$ from obtained at 2500 $\mathrm{kg} \mathrm{cm}^{-2}$ is similar to that at $3300 \mathrm{~kg} \mathrm{~cm}^{-2}$ as shown in Figure 1. The result is shown in Figure 5. It can be seen that the $\gamma$ form diffraction pattern becomes diffuse at $218^{\circ} \mathrm{C}$, and that new diffraction pattern which corresponds to the $\alpha$ form structure appears 
at $220^{\circ} \mathrm{C}$. The transformation is completed at $222^{\circ} \mathrm{C}$, though this temperature corresponds to the beginning temperature of the exotherm observed at $2500 \mathrm{~kg} \mathrm{~cm}^{-2}$ as shown in Figure 1. The temperature of $222^{\circ} \mathrm{C}$ is a little lower than the expected temperature $\left(240^{\circ} \mathrm{C}\right)$ for the transformation. This discrepancy may arise from the difference in the heating rate. From the result shown in Figure 5, it can be directly confirmed that the transformation occurs before melting under high pressure.

On the first order transition, the endotherm is generally observed when the temperature increases, since the entropy change is positive. In this experiment, however, an exotherm was observed. The origin of this exotherm may be explained as follows. Itoh et al. ${ }^{18}$ reported that the free energy of the $\gamma$ form is always higher than that of the $\alpha$ form in the range from room temperature to the equilibrium melting temperature at atmospheric pressure. It is supposed that even under high pressure the $\alpha$ form is more stable than the $\gamma$ form, since the $\alpha$ form is created by crystallization from the melt under high pressure as previously mentioned. Therefore, the transformation may be regarded as a monotropic transition occurring between the metastable and stable states. This assumption is supported by the result that the transformation is irreversible. A monotropic transition occurs at a temperature at which the free energy of both states is not equal. ${ }^{19}$ Hence the enthalpy change becomes negative, i.e., the exotherm is observed, since both changes of the free energy and the entropy are negative.

In addition to the above results, it may be of interest to note that the exothermic peak shifts toward the lower temperature side as the sample absorbs moisture. The effect of the moisture on the transformation is now under investigation, and the results will be reported elsewhere.

It is reasonable to consider that the higher temperature side endotherm, observed in the relatively lower pressure region, is due to the melting of the $\alpha$ form, since the endotherm observed in the pressure range above $2000 \mathrm{~kg} \mathrm{~cm}^{-2}$ is due to the same origin. It is necessary to check the origin of the lower temperature side endotherm and the transformation process in the lower pressure region.

The WAXD patterns of the samples heated up to various temperatures at $1200 \mathrm{~kg} \mathrm{~cm}^{-2}$ are shown in Figure 6. The structure of the sample heated up to the temperature $\left(204^{\circ} \mathrm{C}\right)$ lower than that of the

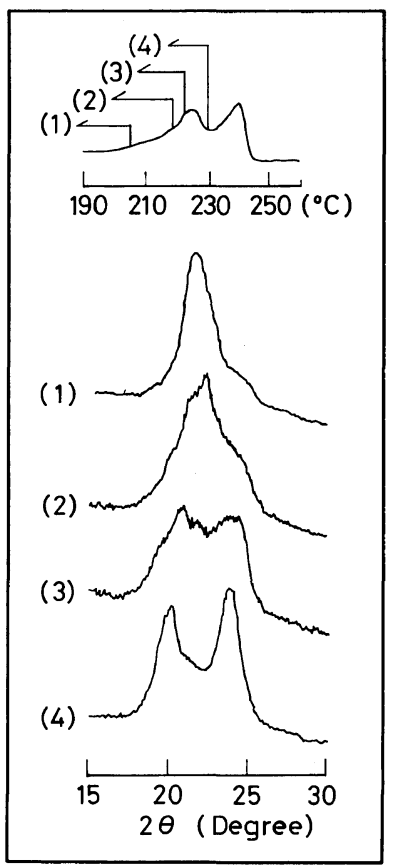

Figure 6. DTA thermogram on heating of the $\gamma$ form crystal at $1200 \mathrm{~kg} \mathrm{~cm}^{-2}$ and WAXD patterns of the samples heated up to various temperatures, (1) $204^{\circ} \mathrm{C}$, (2) $218^{\circ} \mathrm{C}$, (3) $222^{\circ} \mathrm{C}$, and (4) $229^{\circ} \mathrm{C}$, at $1200 \mathrm{~kg} \mathrm{~cm}^{-2}$ followed by rapid cooling.

endothermic peaks shows the $\gamma$ form. However, in the sample heated up to $222^{\circ} \mathrm{C}$ which corresponds approximately to the peak temperature of the lower temperature side endothermic peak, the $\alpha$ form coexists with the $\gamma$ form. The WAXD pattern of the sample heated up to $229^{\circ} \mathrm{C}$, corresponding to the temperature between the two endothermic peaks, shows the $\alpha$ form structure. These results indicate that the transformation begins to occur near the peak temperature of the lower temperature side endotherm, and that a greater part of the $\gamma$ form is transformed into the $\alpha$ form at a temperature between the two endothermic peaks in the experiment at a heating rate of $10^{\circ} \mathrm{C} \mathrm{min}^{-1}$. It is reasonable to consider that the exotherm due to the transformation, evidently not observed in the thermogram, is superimposed on the two endotherms.

To determine the relationship between the results in the high pressure experiment mentioned above and the melting behavior at atmospheric pressure, an experiment at $170 \mathrm{~kg} \mathrm{~cm}^{-2}$, which was the lowest pressure limit in the DTA measurement, was carried 


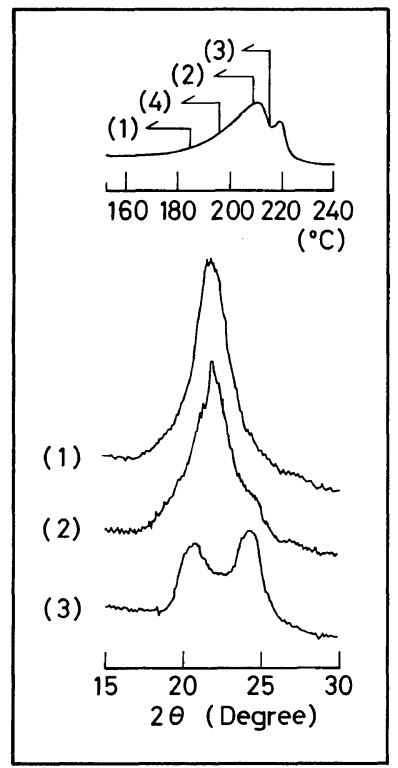

(a)

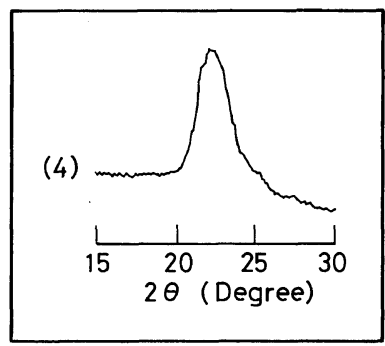

(b)

Figure 7. (a) DTA thermogram on heating of the $\gamma$ form crystal and WAXD patterns of the samples heated up to various temperatures, (1) $185^{\circ} \mathrm{C}$, (2) $209^{\circ} \mathrm{C}$, and (3) $215^{\circ} \mathrm{C}$, at $170 \mathrm{~kg} \mathrm{~cm}^{-2}$ followed by rapid cooling. (b) The sample of WAXD pattern (4) was heated up to $196^{\circ} \mathrm{C}$ at $170 \mathrm{~kg} \mathrm{~cm}^{-2}$ and the temperature was maintained for one hour followed by rapid cooling.

out. The results are shown in Figure 7(a). The sample heated up to $215^{\circ} \mathrm{C}$, a temperature between the two endothermic peaks, shows the pattern of the $\alpha$ from. In the sample heated up to $209^{\circ} \mathrm{C}$ which is around the peak temperature of the lower temperature side endotherm, a considerable part of the $\gamma$ form still remains, in contrast to the result obtained at $1200 \mathrm{~kg} \mathrm{~cm}^{-2}$. A WAXD measurement was carried out on the sample which was rapidly cooled after heat treatment for one hour at $196^{\circ} \mathrm{C}$ and 170

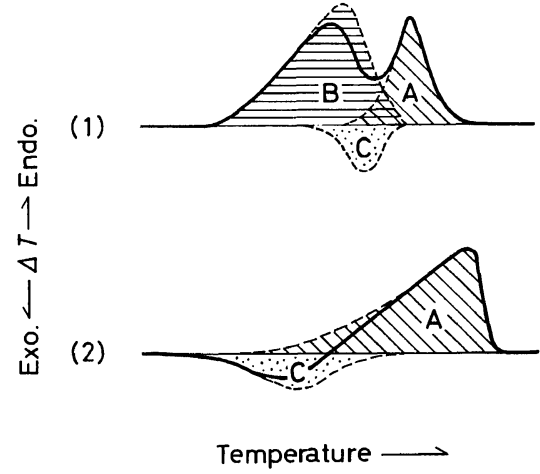

Figure 8. Schematic illustrations of the peak resolutions of thermograms at (1) $1200 \mathrm{~kg} \mathrm{~cm}^{-2}$ and (2) 3300 $\mathrm{kg} \mathrm{cm}^{-2}$. $\mathrm{A}, \mathrm{B}$, and $\mathrm{C}$ denote endotherms due to the melting of the $\alpha$ form crystal, that of the $\gamma$ one, and the exotherm due to the transformation, respectively.

$\mathrm{kg} \mathrm{cm}^{-2}$. The temperature of $196^{\circ} \mathrm{C}$ corresponds to the midslope of the lower temperature side endotherm in the thermogram obtained at 170 $\mathrm{kg} \mathrm{cm}^{-2}$. The results are shown in Figure 7(b). It is evident that the transformation scarcely occurs within one hour, though the sample partially melts. Near atmospheric pressure, the transformation occurs only at a temperature near the melting point of the $\alpha$ form.

Abu-isa ${ }^{11}$ has reported that the $\gamma$ form nylon 6 obtained by iodine treatment is not converted into the $\alpha$ form at atmospheric pressure unless the hydrogen bonding is severely affected by the melting. From the report of Abu-isa and our results shown above, the lower temperature side endotherm, which appears under relatively lower pressure, is due to the melting of the $\gamma$ form.

Figure 8 illustrates peak resolutions in the high pressure DTA thermograms obtained at 1200 and $3300 \mathrm{~kg} \mathrm{~cm}^{-2}$ into the endotherms and exotherm. At $1200 \mathrm{~kg} \mathrm{~cm}^{-2}$, a certain amount of the $\gamma$ form melts, followed by transformation in the residual $\gamma$ form crystal, as the temperature increases. The converted $\alpha$ form then melts at higher temperatures. At $3300 \mathrm{~kg} \mathrm{~cm}^{-2}$, the melting of the $\gamma$ form does not occur since the $\gamma$ form is transformed into the $\alpha$ form at a temperature lower than the expected melting point of the $\gamma$ form at $3300 \mathrm{~kg} \mathrm{~cm}^{-2}$ as extrapolated from the curve of the melting temperature of the $\gamma$ form $v$ s. pressure in Figure 2. The exotherm due to the transformation seems to ap- 
pear as a result of the disappearance of the melting of the $\gamma$ form.

Ito et $a .^{20}$ have reported that in the $\gamma$ form crystal, pressure induces an elongation in the fiber axis direction at room temperature. This means that the molecular chains in the $\gamma$ form, where there is considerable deviation from the planar conformation in the amide group of the chain, tend to take on a planar zigzag-like conformation under high pressure. Therefore, it may be considered that at high pressure and temperature, the $\gamma$ form is transformed into the fully extended planar zig-zag $\alpha$ form.

Acknowledgements. The authors should like to thank Professor T. Takemura of Kyushu University for allowing us the use of the high pressure and high temperature X-ray diffraction measuring system. The authors should also like to thank Dr. M. Yasuniwa for his valuable criticism of the discussion and Mr. S. Hashida for his assistance in the experiments.

\section{REFERENCES}

1. D. R. Holmes, C. W. Bunn, and D. J. Smith, J. Polym. Sci., 17, 159 (1955).

2. H. Arimoto, M. Ishibashi, M. Hirai, and Y. Chatani,
J. Polym. Sci., A, 3, 317 (1965).

3. F. W. Lord, Polymer, 15, 42 (1974).

4. S. Ueda and T. Kimura, Kobunshi Kagaku, 15, 243 (1958).

5. M. Tsuruta, H. Arimoto, and M. Ishibashi, Kobunshi Kagaku, 15, 619 (1958).

6. Y. Kinoshita, Makromol. Chem., 33, 1 (1959).

7. D. C. Vogelsong, J. Polym. Sci., A, 1, 1055 (1963).

8. E. M. Bradbury, L. Brown, A. Elliott, and D. A. D. Parry, Polymer, 6, 456 (1965).

9. H. Arimoto, J. Polym. Sci., A, 2, 2283 (1964).

10. K. Miyasaka and K. Ishikawa, J. Polym. Sci., A-2, 6, 1317 (1968)

11. I. Abu-isa, J. Polym. Sci., A-1, 9, 199 (1971).

12. M. Kyotani and S. Mitsuhashi, J. Polym. Sci., A-2, 10, 1497 (1972).

13. M. Kyotani, J. Macromol. Sci., Phys., B11, 509 (1975).

14. S. Gogolewski and A. J. Pennings, Polymer, 18, 654 (1977).

15. S. Gogolewski and A. J. Pennings, Polymer, 16, 673 (1975).

16. N. Hiramatsu and S. Hirakawa, Polym. J., 12, 105 (1980).

17. K. Matsushige, K. Nagata, and T. Takemura, Jpn. J. Appl. Phys., 17, 467 (1978).

18. T. Itoh, H. Miyaji, and K. Asai, Jpn. J. Appl. Phys., 14, 206 (1975).

19. R. Roy, "Phase Transition," Pergamon Press, New York, 1973.

20. T. Ito, T. Hirata, and S. Fujita, J. Polym. Sci., Polym. Phys. Ed., 17, 1237 (1979). 